\title{
Study On Maldives Tax Law Risk and Its Enlightenment to Chinese Investment Enterprises

\author{
Du Chunyan ${ }^{1, a}$
}

${ }^{1}$ Finance Department of West Normal University, Nanchong, Sichuan Province, P.R.China a898234101@qq.com

Keywords: Tax law, Investment risk, Maldives

\begin{abstract}
Taxation,a basic function of the state's public finance for the property of residents and non-residents, is the most important form of fiscal revenue in the country. With the globalization of capital flows, Chinese enterprises investing in the Maldives becomes a trend. While the legal environment of the two countries is quite different. Therefore, Chinese enterprises should comprehensively analyze the taxation legal systems of China and Maldives and formulate a complete risk prevention mechanism. Meanwhile, it must pay attention to the risks caused by tax violations to promote mutually beneficial cooperation in the investment field between the two countries. This paper analyzes tax laws,tax classifications and discusses the tax law risks of investment in Maldives, and puts forward the countermeasures against risks for Chinese enterprises.
\end{abstract}

\section{马尔代夫税收法律风险及对中国投资企业的启示}

\author{
杜春燕 $1, a$ \\ 1西华师范大学计财处, 南充, 四川, 中国 \\ a898234101@qq.com
}

关键词：税收法律；投资风险；马尔代夫

摘要. 税收是以实现国家公共财政职能为目的, 由政府专门机构向居民和非居民就其财产或 特定行为实施的课税, 是国家一种财政收入形式。随着资本流动的全球化, 中国企业选择投 资马尔代夫成为发展趋势, 但两国的法律环境存在较大差异, 因而中国企业要综合分析中国和 马尔大夫两国税收法律制度, 制定完整的风险防范机制, 同时关注税收违法行为造成的风险, 做好防范工作，才能促进两国投资领域的互利合作。本文分析了马尔代夫税收法律和税种分 类，探讨了投资马尔代夫存在的风险点，结合中国企业的特点提出了税收法律风险防范对策。

\section{1. 引言}

2009年，马尔代夫政府赤字占GDP的 $20.5 \%$ ，政府面临巨大的财政压力。随后，马尔代 夫政府开始进行税制改革, 联合亚洲开发银行 (ADB) 推动经济复苏计划, 2010年成立了马 尔大夫税务局, 随即颁布了科学有效的税法以及税收管理法等法律制度, 为纳税人提供了优 质服务。2011年, 马尔代夫引入了企业所得税和商品服务税, 为政府带来额外收入, 缓解了 财政压力。同时, 亚行加大技术援助力度, 开发税收征管行政管理信息系统, 通过加大税收 征管力度, 提高了税收管理效率, 建立了信息技术平台。2013年, 亚行利用日本扶贫基金会 进一步提供技术援助, 提高马尔代夫税务局的税收政策效力和税务审计能力。2014年通过独 立评估，税务局通过更加多元化的税基和合理的支出，更好的债务管理，提高了预算和财政 
的灵活性。通过多年的税制革新，马尔代夫的税收法律制度得到了逐步的完善和进步。伴随 着中国一带一路的进程，投资马尔代夫成为中国走出去的发展趋势。2016年中国企业对 “一 带一路”马尔代夫投资流量3341万美元，年底存量3578万美元。

\section{2. 马尔代夫税收法律制度}

\section{1 主要税种}

目前马尔代夫的税种主要有进口关税、绿税、商品和服务税(GST)、企业所得税、银行利 润所得税、机场服务费等, 除税收外, 马尔代夫政府也征收公司注册费、特许经营费和机动 车船税等。

2.2.1. 商品和服务税

根据商品和服务税法征收, 征收标准分为普通商品和旅游商品, 普通商品年销售额在100 万卢菲亚以下的不需缴税, 旅游商品一律缴税, 必须在税务局进行注册。自2011年10月 2 日开 始征收, 2011年税率为 $3.5 \%, 2012$ 年提高至 $6 \%$, 自 2013 年 1 月 1 日开始, 旅游商品和服务税升 高至 $8 \%, 2014$ 年再次提高到 $12 \%$ 。

2.2.2. 企业所得税

企业所得税根据商业利润所得税法征收, 该法于2011年1月18日由总统签署。企业所得税 (BPT) 是收取的在马尔代夫进行的所有商业利润的税收。企业所得税一般税率规定如下:对 于本地企业，50万卢菲亚以上税率为 $15 \%$; 对于外商独资和合资企业, 税率一律为 $15 \%$ 。企业 所得税按照财政年度1月1日至12月 31 日进行纳税, 每年分两次缴纳, 上半年税款应在 8 月 31 日前缴纳, 全年税款在次年1月31日前缴纳, 逾期将收取罚息。外国投资企业需遵守企业所得 税法进行纳税，在马尔代夫税务局注册登记，提交有关会计报表等材料，缴纳税款。

\subsection{3.绿税}

根据绿税法规征收, 对留在旅游度假区, 旅游酒店和旅游船上的游客征缴税款。从 2016 年10月 1 日起, 入住旅游宾馆的游客需支付此费用。从旅游度假村, 旅游酒店和旅游船上每天 支付 6 美元的绿税, 旅游宾馆每天支付 3 美元的绿税。马尔代夫本地人和居民许可证持有人不 需要支付绿税。

\subsection{4.汇款税}

根据汇款税法规对在马尔代夫雇用的外国人从马尔代夫转出的资金征收税款。该法规根 据2016年8月25日批准的 “就业法” 第五修正案实施。汇款税按汇出金额的 $3 \%$ 收取。汇款税 于2016年10月1日生效, 规定在马尔代夫经营的银行和汇款机构负责从马尔代夫雇用的外国人 收取汇款税。“在马尔代夫就业的外国人” 是指根据 “马尔代夫移民法” 颁发工作签证的外 国人，只有属于 “工作签证” 类别的外国人才需要缴纳汇款税。

\subsection{5.进口关税}

根据商品不同，按进口货物的到岸价分别征收5\%-200\%的关税。2017年9月，中国和马尔 代夫签署了《中华人民共和国商务部和马尔代夫共和国经济发展部关于结束中国一马尔代夫 自由贸易协定谈判的谅解备忘录》。2017年11月，马尔代夫内阁批准与中国签署马尔代夫一 中国自由贸易协定。中马自贸协定谈判于 2015 年 12 月启动。根据协定，两国间 $95 \%$ 以上的货 物贸易产品将实现零关税。

\section{2 税收法律}

\subsection{1机场税费法}

机场税费法于2016年12月颁布，规定了马尔大夫机场服务费和机场发展费收取范围，支 付方式, 支付有效期限, 生成支付记录等内容。从马尔代夫机场出发的乘客征收机场服务收 费：（1）每名外国旅客25美元；（2）每名马尔代夫乘客12美元。2岁以下的儿童，免收机场 服务费。从马尔代夫经由易卜拉欣 - 纳西尔国际机场的每名乘客, 包括过境旅客, 均应征收 
机场发展费：（1）每名外国旅客25美元；（2）每名马尔代夫乘客12美元。（3）享有外交豁 免权的人员免除机场发展费用。根据机场税费法第 5 条规定，纳税人应在纳税申报的截止日期 前向税务局以美元的方式缴纳机场服务费和机场发展费。未在到期日支付, 将依照税收管理 法予以罚款。

2.3.2商品和服务税法

商品和服务税法于 2011年颁布，分别对商品服务税、免税、零税率商品服务、销项税、 进项税等进行了详细解释, 介绍了商品服务税征收的相关内容: 应税活动范围、商品和服务 税类别、旅游商品和服务、一般商品和服务（表1) 等。对纳税周期、退税程序、税务发票开 具和纳税注册相关事宜进行了明确规定。商品和服务税法规定了免税商品和服务包括: 国 家电力服务、水利设施服务、邮政服务、教育服务、医疗服务、国际运输服务等16项。零税 商品和服务包括：大米、糖、面粉、食用盐、奶制品、食用油等。

表1 商品和服务税率根据时间的划分

\begin{tabular}{|c|c|c|c|c|}
\hline & $2011.10-2011.12$ & $2012.1-2012-12$ & $2013.1-2014.10$ & $2014.11-$ 至今 \\
\cline { 1 - 4 } 旅游商品服务税率 & \multirow{2}{*}{$3.5 \%$} & $6 \%$ & $8 \%$ & $12 \%$ \\
\cline { 1 - 4 } 一般商品服务税率 & \multirow{3}{*}{$6 \%$} & \multicolumn{3}{|c}{$6 \%$} \\
\cline { 3 - 5 }
\end{tabular}

\subsection{3商业利润所得税法}

商业利润所得税法于2011年1月颁布, 规定了对马尔代夫以外的来源的利润征税，对企业 所得税, 其他所得税, 特许权使用税费进行了明确规定: 在马尔代夫居住或开展业务的公司, 合伙人, 个人和所有人员将根据本法受到征税。此外，任何人向非居民支付的某些款项也将 根据本法受到征税。公司, 合伙人和其他人的税率为 $15 \%$, 利润来自马尔地夫以外的来源税 率为 $5 \%$, 预扣税 $10 \%$ 。对于特许权使用费, 按 $10 \%$ 的税率征税。

\subsection{4税收管理法}

2010年税收管理条例草案通过马尔代夫人民议会第一次会议, 颁布了税收管理法。该法 的颁布主要是为了加强税收征收管理, 规范税收征收和缴纳行为, 保障国家税收收入, 保护 纳税人的合法权益, 促进经济和社会发展。税收管理法中规定了税务局的成立、税务局各部 门的功能、税务人员任职资格及相应的职责。该法还明确了税务局有审计和调查的权利, 对 于不缴纳税款的情况有权扣押土地和财产或从第三方收回税款的权利, 相关双重征税减免规 定，以及税收法庭成立条件、相关犯罪行为和刑罚规定。

\subsection{5海关法}

海关法于2011年4月颁布，规定了海关服务的目标，权力，责任和特权。海关法的出台是 为了确保马尔代夫海关体系运行稳定; 保护国家财产, 强化运营体系; 通过检查进出马尔代夫 的嫌疑人和货物, 特别是检查抵达和离开马尔代夫的工艺品, 加强对官方贸易口岸管理, 制 止非法物品的进出口; 确立与海关有关的原则; 该法规定 “马尔代夫海关服务机构” 是官方机构, 依照相关规定管理与该服务有关的活动。马尔代夫海关部门应由共和国总统指定的部长监督。

\section{3. 税收法律风险}

中国企业投资不仅要了解马尔大夫的税法税制, 还要熟悉我国与马尔代夫签订的税收协 定，应对双重征税负担。具体来说，中国企业投资的税收风险主要有以下几种。

\section{1税收管辖权重叠风险}

当中国和马尔代夫分别使用两种不同的税收管辖权时, 就会对跨国企业的同一经营业务 进行重复征税, 加重企业的税收负担。由于中国对企业行使居民管辖权, 马尔代夫同时对企 业行使地域管辖权, 两种管辖权重叠造成企业境外投资被重复征税。中国采用的是居民管辖 权和来源地管辖权相结合的形式，即居民企业对其所得全面纳税，非居民企业只需履行有限 
纳税的义务。企业属于居民企业, 其境内外经营所得都要缴纳所得税。企业通过境外投资获 得的生产经营利润、投资收益和财产收益都要面临两个国家重复征税所带来的税收风险, 加 重了企业的税收负担。

\section{2税制差异风险}

中国与马尔代夫的税收制度存在较大差异。由于中国和马尔代夫没有签订税收协定，中 国企业的税制主要有 28 个税种。而马尔代夫的税种较少, 集中在商品服务税和企业所得税两 个税种。马尔代夫税务局数据显示, 2014年上半年国家税收达到 56.7 亿卢菲亚, 同比增长 $22 \%$ 。 其中商品和服务税占 $41.2 \%$, 商业税占 $24.6 \%$ 。税制的不同使企业进行纳税时会产生困惑, 适应 了中国的税收制度，对马尔代夫各税种缺乏认识，容易给企业带来经济损失。

\section{3税收协定风险}

伴随着国际关系的不断发展，马尔代夫为吸引外资会制定各种税收优惠政策，中国企业 在投资前如果不知道马尔代夫是否与中国签订了税收协定以及协定具体内容, 忽略其中关于 税收抵免等具体规定, 不及时进行税收筹划, 利用协定中的优惠政策, 合理规避重复征税, 容易增加企业税收成本, 加重企业负担, 最终很难在马尔代夫得到发展。

\section{4. 风险防范策略}

\section{1掌握马尔代夫税法}

中国企业要充分了解马尔代夫的税种、税率、抵免政策，投资决策前熟悉马尔代夫的税 制, 了解税法对投资领域是否有特殊的规定和税制差别对企业投资可能产生的影响。考虑马 尔代夫税法与我国税法中的税收管辖权重叠, 探索如何降低税收成本。掌握马尔代夫的税法 的基础是获取充足的税收信息, 从马尔代夫税务局网站上获取, 正式公布的法规政策是最权 威的税法信息，可以借助马尔代夫地方成功运营的中国投资企业收集税收信息。对企业内部 的财税人员进行初步的整理与测算, 因此企业需要培养精通财务、税收、外语的风险管理人 才, 为企业管理好税收风险提供软实力。财税人员在关注企业日常经营工作的同时, 还要深 入马尔代夫企业经营状况、经营内容、税收政策等, 将各种影响因素综合起来分析, 设计纳 税筹划备选方案, 并选择最优方案, 使纳税筹划的成本和风险降到最低。

\section{2建立税收风险内部控制体系}

中国企业在投资决策前就要充分认识到企业在境外投资经营可能面临的税收风险。在投 资决策阶段, 企业应进行税收风险识别与评估, 分析税收风险的严重性和对企业总体税负的 影响, 为建立税收风险管理体系打下基础。根据评估识别出来的税收风险, 在马尔代夫税法 体制下，建立一套税收风险内部控制体系，通过健全的税收风险防范机制应对风险，提高税 收风险管理效益。从收集税收风险信息到识别、分析及评价税收风险最后应对税收风险的一 整套系统设计。针对识别出来的税收风险, 设计出具体的税收风险信息沟通系统与风险监控 流程。结合马尔代夫的具体税法规定, 企业主营业务、战略目标等实际情况加以调整, 在不 影响企业国际经营战略的前提下，合法地谋求税收利益最大化。

\section{References}

[1] Zhao Jinlei.Analysis on the Legal Risks of Enterprises' Overseas Investment and Their Countermeasures,Legality Vision,vol.31,pp.251,2015.

[2] Li Xiangju, Wang Xiongfei.Assessment of Tax Revenue Risk of the Chinese Corporate Overseas Inveshnent under"The Belt and Road Initiative,Taxation Research,vol.2,pp.9-13,2017. 